This item was submitted to Loughborough's Research Repository by the author.

Items in Figshare are protected by copyright, with all rights reserved, unless otherwise indicated.

\title{
Using mobility as a conceptual framework for informing the design of mobile ICT for construction professionals
}

PLEASE CITE THE PUBLISHED VERSION

PUBLISHER

(c) The Association for Computing Machinery

LICENCE

CC BY-NC-ND 4.0

REPOSITORY RECORD

Mitchell, Val, Andrew May, Sarah L. Bowden, and Tony Thorpe. 2019. "Using Mobility as a Conceptual Framework for Informing the Design of Mobile ICT for Construction Professionals". figshare. https://hdl.handle.net/2134/2804. 
This item was submitted to Loughborough's Institutional Repository by the author and is made available under the following Creative Commons Licence conditions.

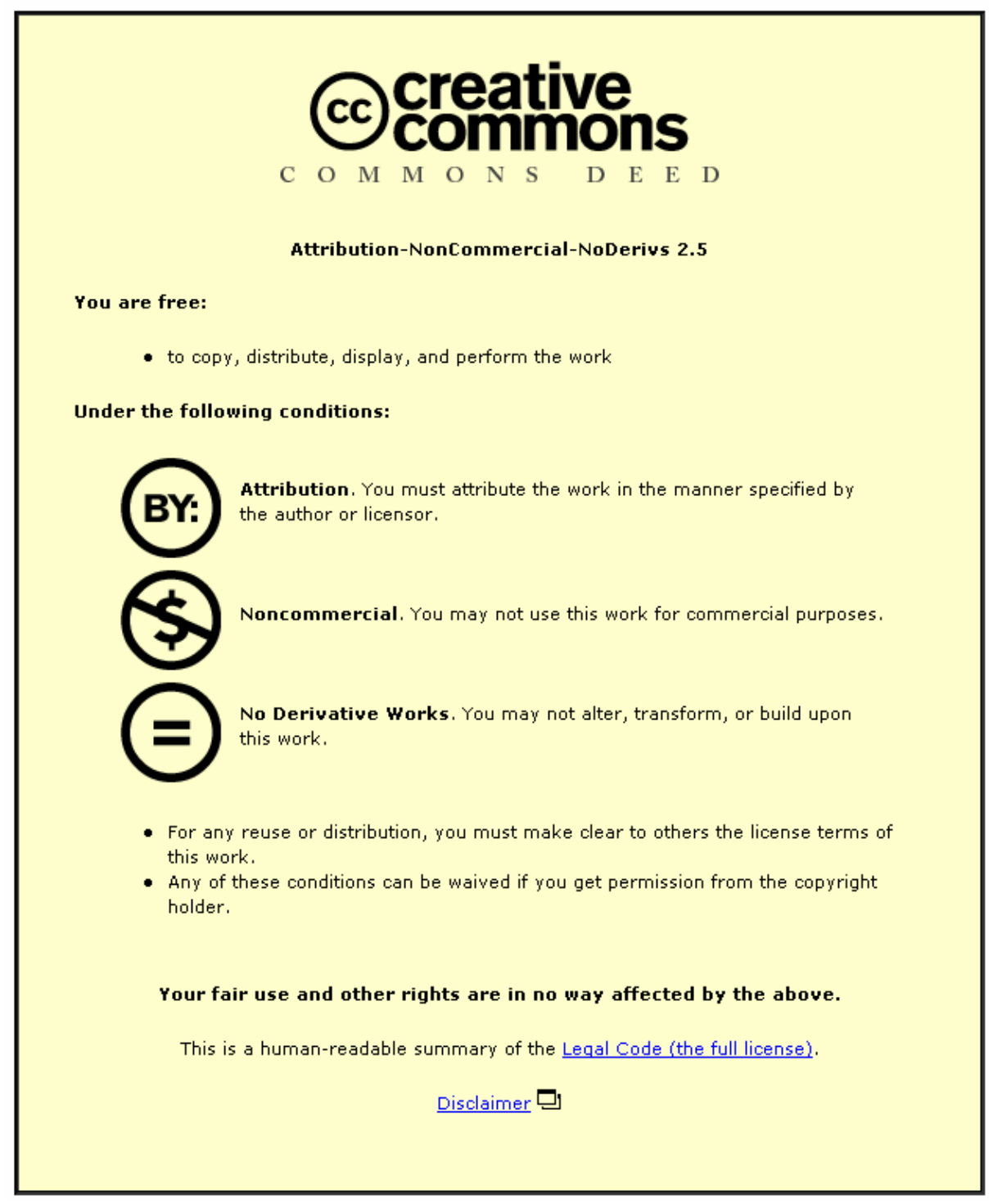

For the full text of this licence, please go to: http://creativecommons.org/licenses/by-nc-nd/2.5/ 


\section{Using Mobility as a Conceptual Framework for Informing the Design of Mobile ICT for Construction Professionals}

\author{
Val Mitchell \\ ESRI \\ Holywell Building \\ Holywell Way \\ Loughborough \\ LE11 3UZ, UK \\ +44 (0)1509 226967 \\ v.a.mitchell@lboro.ac.uk
}

\author{
Andy May \\ ESRI \\ Holywell Building \\ Holywell Way \\ Loughborough \\ LE11 3UZ, UK \\ +44 (0)1509 226906 \\ a.j.may@lboro.ac.uk
}

\author{
Sarah Bowden \\ Arup \\ 13 Fitzroy Street \\ London \\ W1T 4BQ, UK \\ +44 (0) 2077553177
}

sarah.bowden@arup.com

\author{
Tony Thorpe \\ Dept. of Civil \& Building \\ Engineering \\ Loughborough \\ University \\ LE11 3TU \\ +44 (0)1509223771 \\ a.thorpe@ Iboro.ac.uk
}

\begin{abstract}
This paper illustrates how the concept of mobility can be used to consider how contextual factors shape user requirements for mobile ICT. The spatial, temporal and contextual mobility of construction professionals is described based on fieldwork conducted within the UK. A distinction between the mobility of workers when they are operating remotely within a geographically distributed team and when they are working cooperatively with others co-located on site is reported. The implications of this finding are discussed in relation to the mobile ICT needs of construction professionals.
\end{abstract}

\section{Categories and Subject Descriptors}

H.1.2 [Models and Principles]: User/Machine Systems - human factors

\section{General Terms}

Design, Human Factors.

\section{Keywords}

construction industry, mobility, user-centered design, human factors

\section{INTRODUCTION}

Mobile information and communication technologies (ICT) offer great potential to improve business processes within the construction industry. Construction professionals are highly mobile - they are often based in temporary offices on site (figure 1); can spend considerable time traveling between sites and often roam extensively on site. Effective mobile ICT can potentially increase the quality of construction work (e.g. adherence to design specifications), and reduce time and costs by streamlining processes and reducing re-work (e.g. access to late design

Permission to make digital or hard copies of all or part of this work for personal or classroom use is granted without fee provided that copies are not made or distributed for profit or commercial advantage and that copies bear this notice and the full citation on the first page. To copy otherwise, or republish, to post on servers or to redistribute to lists, requires prior specific permission and/or a fee.

MobileHCI'06, September 12-15, 2006, Helsinki, Finland.

Copyright 2006 ACM 1-59593-390-5/06/0009...\$5.00. changes) [1]. Mobile ICT solutions have been implemented successfully within the industry, and some have even achieved a return on investment within one year $[5,13]$. However, a more general observation by [2] suggests that the uptake of innovative ICT within the construction industry is disappointing given the research effort involved and the multi-million pound nature of many of the commercial contracts.

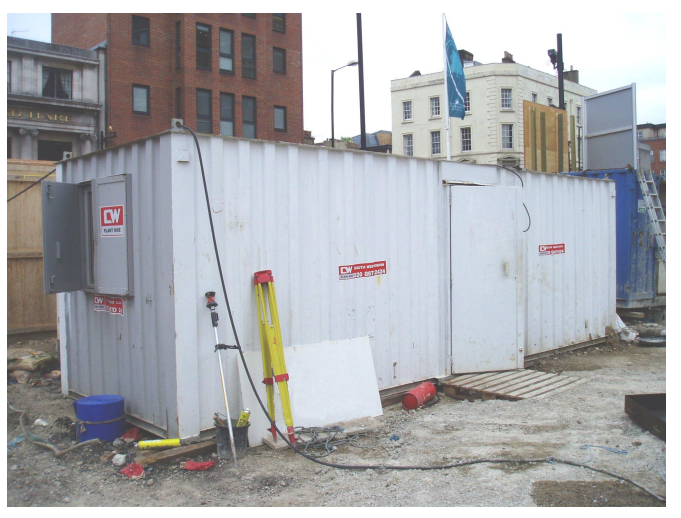

Figure 1 site offices can be basic

Key barriers to mobile ICT adoption have meant that the technological capabilities demonstrated by suppliers have often failed to be translated into business impact in the real world. One such barrier is a poor understanding of the real needs of the mobile end user, over and above the provision of connectivity; the digital replication of existing paper-based processes, and the automation of data capture and transmission. Central to achieving efficient, effective and satisfying product solutions is an understanding of the context within which product use takes place [7]. However the sheer variety of contexts experienced by mobile product users makes it very difficult to capture context in a form useful for informing product design [12]. In order to articulate context in a meaningful way, this paper uses the concept of mobility to explore how contextual factors shape current use of mobile ICT within the construction industry. Typical examples of the spatial, temporal and contextual mobility $[6,8]$ of construction professionals are presented. How the mobility of these users could potentially be enhanced through the provision of user-centered mobile ICT solutions is then discussed.

Mobility - the quality of being mobile - has been studied from various perspectives including as primarily a theoretical concept 
$[6,8,14]$ as a factor shaping user requirements within the context of collaborative work $[3,10]$ and in relation to its impact upon product interaction [9]. Although researchers use different parameters to categorize mobility, there is general agreement that the opportunity to work 'Anytime, Anywhere' typically used to promote mobile ICT solutions does not adequately describe the realities of mobile ICT interaction within real world contexts [11]. "Mobility should not and cannot be understood as a matter of [dynamic] location in time and space" [6]. It is more important to understand how opportunities for interaction with people and resources (objects and data) potentially extended though the provision of mobile ICT are tempered by dynamic and interrelated contextual factors (both physical and social). Understanding how these factors shape user requirements is key to successful implementation of mobile ICT.

\section{METHODOLOGY}

This paper draws on data from two case studies of mobile working undertaken with construction companies within the COMIT (Construction Opportunities for Mobile IT) project. This was a two year project funded by the UK DTI, the aim of which was to promote the development and uptake of mobile ICT within the construction industry. COMIT comprised approximately 40 construction companies, IT developers, research and dissemination groups. Two construction processes identified within COMIT as fertile areas for the introduction of mobile ICT formed the basis for this research. These were Health and Safety inspection and Design Problem Resolution.

Contextual interviews were conducted during 6 one day site visits combining observation, discussion and reconstruction of past events. The sites visited were diverse including a new football stadium, a school extension, a supermarket and city centre offices. In the tradition of contextual inquiry [4] the researchers took the role of apprentices to the construction professionals shadowing tasks and helping where possible with practical tasks (figure 2). Special attention was given to examination of how paper based and ICT resources were used to support working processes and localized and distant communication with colleagues and other site workers. The data was supplemented by study of business process documentation derived from within the COMIT project.

The mobility of the construction professionals studied has been examined using fieldwork and supporting data. Three interrelated dimensions of mobility adapted from Kakihara and Sorensen [8] have been used to structure consideration of mobility: Spatial Mobility: - the geographical movement of people and related resources. Temporal Mobility - how freedom from linear 'clock' time, enabled by mobile ICT is affected by social and cultural dimensions of time that determine how and when it is acceptable to interact with others. Contextual Mobility - how the freedom to interact with other people and resources 'anywhere anytime,' provided hypothetically by mobile ICT solutions, is tempered by contextual factors that shape whether interaction is possible, desirable or acceptable. Rather than seeking to provide a full theoretical description of the mobility of a specific group of workers, the aim has been to use the concept of mobility as a thinking tool for structuring consideration of context in a way that can be used to effectively inform the design of mobile ICT solutions. Space precludes the presentation of full results. Instead examples are included for each dimension in order to illustrate the approach.

\section{RESULTS}

Spatial Mobility: The spatial mobility of construction professionals is manifested as travel between sites and central offices and as movement within sites. Sites can be dispersed over a wide geographic area and professionals may be required to visit a number of sites in one day. Others may be based on one site for months at a time. Whilst on site, professionals will usually be based in temporary office accommodation from which they will frequently visit site locations e.g. to monitor activities or troubleshoot problems. Sites can be a few 100 meters in dimension e.g. city centre sites or can stretch for many kilometers e.g. road construction. Movement around site may include climbing to locations high above the ground using temporary walkways and ladders. The physical resources with which workers interact are also highly mobile. The physical layout of each site continually changes as building progresses thereby altering the location of work teams, equipment and tools. Equipment and vehicles are frequently moved between sites to maximize use of expensive resources.

Spatial mobility is therefore intrinsically shaped by the demands of the job. Mobile ICT in the form of mobile phones and laptop PCs have done much to support this pattern of mobility by increasing connectivity to others and to centralized information resources. However use of mobile ICT solutions often takes place within the site office rather than out on the construction site.

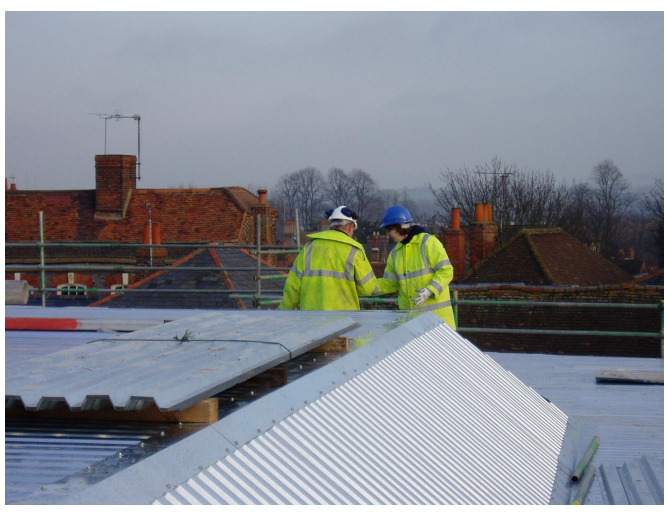

Figure 2 fieldwork in progress

Temporal Mobility: The time when construction work takes place is rarely dictated by conventions of the working day. Although most workers will have prescribed working hours, when work can actually take place will be determined by environmental factors e.g. the weather and time of day and by the progress of others. Short winter days will require work to stop when daylight fails and rain or wind can halt many construction processes. However modern construction projects negotiated in a competitive marketplace often face significant time pressures in order to avoid penalties for late delivery. Therefore work may start early and finish late if timescales are tight. Construction also frequently requires the coordination of a number of project teams from different contractors and sub-contractors whose start and end dates for work completion will be dependant on others completing their tasks. Therefore scheduling of activities and resources will often require last minute changes and negotiation between parties within the supply chain. Design changes may be frequent requiring careful version control for documents and drawings. Construction professionals are also likely to experience times when they are unavailable to interact remotely with others. When traveling, connectivity maybe limited to a (hopefully) hands-free 
mobile phone connection. When out and about on site, noise, hazards and poor weather may make even phone connectivity impossible or undesirable. The temporal mobility of construction professionals can therefore be restricted by many factors leading to a strong reliance upon asynchronous rather than synchronous communications for both social and business communications.

Contextual Mobility: From the time spent on site shadowing and interviewing construction professionals it was evident that the harsh and potentially hazardous environment on site often limited the number of contexts where use of existing mobile ICT solutions was either possible or desirable. Interaction with devices can be constrained by wearing protective gloves for safety or warmth. Two-handed interaction with devices maybe prevented by needing to interact with other resources e.g. paper based plans or when insecurely located on platforms or ladders. Interaction is also restricted by a compelling need to maintain safety by frequently monitoring other activities in the vicinity of use. Other barriers include poor visibility of screen based information due to glare and excessive noise and vibration.

Despite these barriers to interaction, many mobile ICT suppliers have sought to use PDAs and other handheld terminals to provide electronic versions of previously paper based resources. Examples include solutions that offer enhanced efficiency by providing on site access to centralized computer files (e.g. the latest design specifications) and solutions that improve data capture by reducing the need to transfer data from paper to computer at a later time. Well crafted applications will take into account the harsh physical context of use and will seek to minimize interaction through well designed menu structures offering task relevant information rather than direct duplication of $\mathrm{PC}$ based applications. However, whilst promising increased spatial and temporal mobility these applications often fail to take sufficient account of contextual factors. For example, where there is no compelling need (at least from the perspective of the end user) to enter data electronically out on site, the fieldwork data showed workers choosing to delay data entry until they returned to the site office (e.g. by scribbling notes on paper or mentally retaining information). This can lead to the paradoxical situation where workers interact with devices with limited functionality designed to be used when mobile whilst sitting stationary in the site office. Applications designed to exploit the enhanced processing power, display quality and interaction capabilities offered by modern laptop PCs are in such cases more suited to the needs of the professional construction worker even though enhanced mobility is neither promised nor achieved.

Leading construction companies use sophisticated ICT applications often supported by broadband connectivity to enhance business processes and effectively manage projects within an extremely competitive and time pressured marketplace. However the weak link in the chain has traditionally been communications to and from the construction site. It is commonplace in the UK to wait several months for telephone and data connections to be provided to a construction site. In the meantime access even to email is problematic and access to the latest versions of project plans and construction specifications may require physical trips to the head office. Not surprisingly, it was evident from the fieldwork that many construction professionals valued connectivity over and above mobility. Providing wireless broadband to a site office via a laptop can greatly improve working efficiency without the need to pay for and wait for a telecommunication connection. Such solutions provide a valued extension to centralized company networks enabling construction professionals to experience communication and information access that comes close to matching the quality of provision they are used to when based back at head quarters.

A further promise offered by mobile ICT providers is the opportunity for temporal mobility to be extended through the provision of ICT solutions that make construction professionals more accessible regardless of their location on site. However consideration of the fieldwork data has shown that communications to colleagues and other project stakeholders offsite rarely needs to be synchronous as the distributed nature of modern construction processes seldom allows instantaneous decision making. Where direct communication with others off site is required then the immediacy and richness of voice communications in conjunction with supporting emails is again best supported within the relative quiet of the site office.

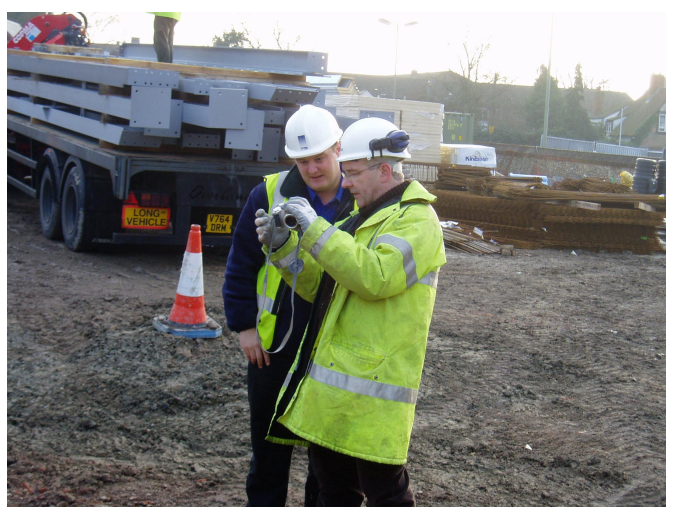

Figure 3 sharing digital photos on site

In contrast to the nature of remote working relationships with colleagues off site, interaction with others on site was seen to be very social, predominately face to face and opportunistic. The construction professionals observed within the fieldwork were highly mobile when they needed to communicate with others on site. A large construction site can at anytime contain many teams from different companies whose activities are coordinated by a project manager also based on site. Communications between stakeholders on different teams were observed to take place predominately face to face even when email and telephone communications were available. Similarly when interacting with construction teams in a line management capacity, professionals would tend to wander out to see a foreman or site manager on site when problems arose, showing a desire to deal with issues in situ where it was easier to articulate both problems and potential solutions. Successful construction professionals also demonstrated an ability to negotiate rather than coerce others to comply with regulations or put right construction errors. Strong social skills were obviously an important asset for management personnel when co-operating on site with manual workers used to operating within a harsh and physically demanding environment. Making the best of opportunities to inform and persuade was therefore an important part of on site construction management. Mobile ICT has the potential to enhance such communications. Figure 3 shows a Health and Safety manager using digital images displayed on his camera screen to illustrate a potential safety problem to a site manager. In this circumstance mobile ICT has enhanced the mobility of the user by providing rich contextual information at 
the point of need (in this case during an impromptu conversation). The construction professionals' overt desire to be mobile when collaborating with others on site suggests that there are opportunities to develop innovative mobile ICT solutions that support this behavior. Opportunities include solutions that support face to face sharing of contextual data captured on site but seek to augment this data in ways that can facilitate cooperative decision making or the consideration of design trade offs. For example, in the future location enhanced mobile services could automatically link photos and sketches created on site to plans and drawings relevant to that location.

\section{CONCLUSION}

Consideration of the spatial, temporal and contextual mobility of construction professionals has identified a distinction between the mobility of workers when they are operating remotely within a geographically distributed team and when they are working cooperatively with others co-located on site. When in the role of remote worker, connectivity rather than enhanced mobility was most highly valued. In this context spatial and temporal mobility is limited by contextual factors that inhibit truly mobile use of ICT. Workers were seen to choose to delay interaction with other people and resources until sitting in the site office rather than interacting with mobile devices when out and about on site. However ICT solutions that provided connectivity between the site office and centralized data resources were widely utilized where available and highly desired when telecommunication services were limited. Therefore mobile broadband solutions offer significant benefits to remote workers but should be envisaged predominantly as a means for extending centralized ICT services to the site office rather than as an opportunity to extend the performance of existing office based tasks into the hostile on site environment. In contrast when working collaboratively with colleagues on site, construction professionals are highly mobile choosing to resolve problems in situ as well as seeking to make the best of social opportunities to influence and inform others as they seek to meet their operational goals. It is therefore suggested that attention is shifted from developing mobile ICT solutions that extend the office network beyond the site office to the identification of solutions that enhance co-operative work on site.

This research has illustrated how structured consideration of mobility can be used as a conceptual framework for informing the design of mobile ICT within the context of construction work. COMIT which is continuing as a self funded network of construction companies, mobile ICT suppliers and other interested parties will provide the opportunity to verify these conclusions as further mobile ICT applications are trialed and evaluated. The research will also be extended to identify whether the mobility characteristics of construction professionals are mirrored by other groups of mobile workers in order to increase the applicability of this work.

\section{ACKNOWLEDGMENTS}

The authors would like to acknowledge the contributions made by the COMIT community. Further details of COMIT, and the partners involved, can be found at www.comitproject.org.uk.

\section{REFERENCES}

[1] Anon. (2005) Construction: Can the Sleeping Giant be Roused? Mobile Enterprise Analyst (January, 2005), 4-14

[2] Anumba, C. J. (1998) Industry Uptake of Construction IT Innovations - Key Elements of a Proactive Strategy, In: The Life-cycle of Construction IT Innovations - Technology Transfer from Research to Practice. B. C. Bjoerk \& A. Jagbeck, eds., Stockholm, pgs 77-83.

[3] Bellotti V and S Bly (1996) Walking Away from the Desktop Computer: Distributed Collaboration and Mobility in a Product Design Team. $6^{\text {th }}$ Conf. on Computer Supported Cooperative Work

[4] Beyer, S. and K Holtzblatt (1998) Contextual Design. Defining Customer-Centred Systems. Morgan Kaufmann Publisher Inc.

[5] Bowden, S., Dorr, A., Thorpe, A., Anumba, C. J., \& Gooding, P. (2005) Making the Case for Mobile IT in Construction. International Conference on Computing in Civil Engineering, (Cancun, Mexico, July 12-15). ASCE.

[6] Fallman, D. (2005) From Freedom to Involvement: On the Rhetoric of Mobility in HCI Research. $38^{\text {th }}$ Hawaii Int. Conf. on System Sciences Big Island Hawaii, January 3-6

[7] ISO (1999) ISO 13407: Human Centred Design Processes for Interactive Systems. Geneva, International Standards Organization

[8] Kakihara, M. and C Sorensen (2002) Mobility: An Extended Perspective. Hawaii Int. Conf. on System Sciences. Big Island Hawaii Jan 7 -10

[9] Kristoffersen S and F Ljungberg (1998) Representing Modalities in Mobile Computing: A Model of IT Use in Mobile Settings. Interactive Applications of Mobile Computing (IMC'98) Rostock, Germany

[10] Luff P. and C Heath (1998) Mobility in Collaboration $7^{\text {th }}$ Conf. on Computer Supported Cooperative Work CSCW 98 Seattle Washington USA

[11] Perry, M., O’Hara, K., Sellen, A., Brown, B., Harper, R. (2001) Dealing with Mobility: Understanding Access, Anytime, Anywhere. ACM Transactions on Computer Human Interaction (TOCHI), Vol 8, No. 4, Dec. 2001

[12] Tamminen, S.,A. Oulasvirta, K. Toiskallio and A Kankainen (2003) Understanding Mobile Contexts Mobile HCI $20035^{\text {th }}$ International Symposium, Udine, Italy, Springer-Verlag

[13] Ward, M., Thorpe, A., Price, A., \& Wren, C. (2003) SHERPA: Mobile wireless data capture for piling works. Journal of Computer Aided Civil and Infrastructure Engineering, 18, 4 200-220.

[14] Weilenmann, A. (2003) Doing Mobility: Towards a New Perspective on Mobility. $26^{\text {th }}$ Information Systems Research Seminar in Scandinavia (IRIS 2003), Helsinki, Finland 